\title{
Redox poise and oxygenation of cytochrome bd in the diazotroph Azotobacter vinelandii assessed in vivo using diode-array reflectance spectrophotometry
}

\author{
Eugene P. Kavanagh, ${ }^{1}$ James B. Callis, ${ }^{1}+$ Sian E. Edwards, ${ }^{1,2}$ \\ Robert K. Poole ${ }^{3}$ and Susan Hill ${ }^{1}$
}

1 Nitrogen Fixation Laboratory, John Innes Centre, Norwich NR4 7UH, UK

2 Division of Life Sciences, King's College London, Campden Hill Road, London W8 7AH, UK

3 Department of Molecular Biology and Biotechnology, The University of Sheffield, Sheffield S10 2TN, UK
Author for correspondence: Susan Hill. Tel: +44 1273 474017. Fax: +44 1603454970. e-mail: shill@pavilion.co.uk

\begin{abstract}
A ferrous oxygenated form of cytochrome $d$ is characteristic of all cytochrome bd-type oxidases so far examined, but its participation in enzyme turnover is unclear. It is relatively stable, occurs in aerated cell suspensions and predominates during enzyme preparation. In this study, diode-array reflectance spectrophotometry was used to assess the redox poise and oxygenation of cytochrome bd in vivo, in the aerobic diazotroph Azotobacter vinelandii. Mutants either lacking or overproducing the cytochrome bd oxidase were used to confirm the reliability of the optical configuration. Changes in absorbance attributed to cytochromes $b, c$ and $d$ were followed as the $\mathrm{O}_{2}$ supply was altered either in suspensions of harvested cells or during steadystate growth. In washed cell suspensions, three states of cytochrome $d$, which differed in absorbance characteristics, were seen: (1) an oxygenated form that absorbs at $650 \mathrm{~nm},(2)$ a form which has little absorbance at either 650 or $630 \mathrm{~nm}$ and (3) the reduced form that absorbs at $630 \mathrm{~nm}$. The transition between states 2 and 3 , but not 1 and 2, correlated with the changes in the redox states of cytochromes $b_{595}$ and $b_{560}$. The dissolved $O_{2}$ concentration at which this transition occurred coincided approximately with the apparent $\mathrm{O}_{2}$ affinity for the oxidase in vivo (approx. $5 \mu \mathrm{M}$ ). During steady-state growth, the cytochromes were partially reduced and the oxygenated form of cytochrome $d$ was undetected. These in situ measurements support the view that an oxygenated form of cytochrome d (absorbing at $650 \mathrm{~nm}$ ) in the one-electronreduced cytochrome bd-type oxidase does not take part in enzyme turnover.
\end{abstract}

Keywords: Azotobacter vinelandii, cytochrome $b d$-type oxidase, $\mathrm{O}_{2}$ supply and redox changes of cytochromes, diode-array spectrophotometry

\section{INTRODUCTION}

Members of the genus Azotobacter are obligately aerobic heterotrophs, which can fix $\mathrm{N}_{2}$ in the free-living state. An understanding of how aerobic organisms can fix $\mathrm{N}_{2}$ has long been a focus for investigation, because $\mathrm{N}_{2}$ fixation catalysed by the nitrogenases is a strictly anaerobic process. Respiration in organisms capable of

†Present address: Department of Chemistry, University of Washington, Seattle, WA 98195, USA.

Abbreviations: DARS, diode-array reflectance spectrophotometry; DOC, dissolved oxygen concentration. aerobic $\mathrm{N}_{2}$ fixation has at least two functions: to provide adequate ATP for the energy-intensive process of $\mathrm{N}_{2}$ fixation, and to remove excess $\mathrm{O}_{2}$ as part of the mechanism to protect nitrogenase from inactivation by $\mathrm{O}_{2}$. Azotobacter vinelandii has the ability to fix $\mathrm{N}_{2}$ over a wide range of $\mathrm{O}_{2}$ concentrations. This ability, although not fully understood, involves in part changes in the synthesis and activities of components of the respiratory chain and of those supplying electrons for respiratory activity (see reviews by Yates, 1988; Hill, 1992; Poole \& Hill, 1997).

The respiratory chain of Azotobacter vinelandii is branched at both ends. Several dehydrogenases feed 
electrons into a quinone pool. Subsequently, the flow of electrons proceeds to two, or possibly three, different terminal oxidases, dependent upon the electron pressure, the prevailing oxidase concentrations and their affinities for $\mathrm{O}_{2}$. Mutational and gene expression studies have revealed that the cytochrome $b d$-type quinol oxidase plays an essential role in the removal of $\mathrm{O}_{2}$ under conditions of high $\mathrm{O}_{2}$ input (Kelly et al., 1990; Leung et al., 1994; D'mello et al., 1997; Wu et al., 1997). It has a relatively high apparent $K_{\mathrm{m}}$ (low affinity) for $\mathrm{O}_{2}$ (D'mello et al., 1994a). The alternative terminal oxidase, of the haem-copper type (Yang, 1986; Leung et al., 1994), has a higher apparent affinity for $\mathrm{O}_{2}$ (D'mello et al., 1994a), whereas a putative third oxidase may have an even higher apparent affinity (D'mello et al., 1994a).

The cytochrome $b d$-type quinol oxidase of $A$. vinelandii is similar to that of Escherichia coli. The genes (cydAB) encoding the subunits (Green et al., 1988; Moshiri et al., 1991), and the structure and properties of the enzymes (Kita et al., 1984; Kolonay et al., 1994; Jünemann \& Wrigglesworth, 1995) all share common features. One striking difference between them is their apparent $K_{\mathrm{m}}$ for $\mathrm{O}_{2}$, the value, either in vitro or in vivo, being much lower for the $E$. coli than for the A. vinelandii enzyme (D'mello et al., 1994a, 1996; Jünemann et al., 1995). This feature probably reflects differences in the rate of electron donation to the enzyme complexes (Jünemann et al., 1995). The $A$. vinelandii enzyme, like that of $E$. coli, contains one mole each of haem $d$, haem $b_{595}$ (high spin) and haem $b_{558}$ (low spin), although the $\alpha$-peak of the low-spin $b$ is quoted as $560 \mathrm{~nm}$ by Kolonay et al. (1994) and Jünemann \& Wrigglesworth (1995).

Early studies of cytochrome $b d$ in $A$. vinelandii revealed a spectral form of the oxidase with a distinctive absorption maximum at $650 \mathrm{~nm}$ (Kauffman \& van Gelder, 1973). As in the pioneering work of Keilin (1966), this form was initially ascribed to the oxidized form of the enzyme, since it was generated by shaking suspensions of cells or membranes in air. However, lowtemperature experiments with $E$. coli cells and membranes revealed that a form of the oxidase absorbing at $650 \mathrm{~nm}\left(d_{650}\right)$ was observed immediately after photolysing the CO-ligated species in the presence of $\mathrm{O}_{2}$ and before redox changes could be observed by EPR (Poole et al., 1983). On the basis of these experiments and reanalysis of earlier data, Poole $e t$ al. (1983) proposed that cytochrome $d_{650}$ is an oxygenated or oxy-complex in which the haem $d$ remains reduced. It was suggested (Poole et al., 1983) that the oxidized form of the oxidase lacks distinct features in the red region of the spectrum and may be equated with the $\left(d_{x}\right)$ form described by Kauffman \& van Gelder (1973). Subsequent studies of membrane-bound and purified cytochrome $b d$ from $A$. vinelandii and $E$. coli have led to a model for the catalytic cycle of $\mathrm{O}_{2}$ reduction in which one (Kahlow et al., 1991) or two forms of oxygenated cytochrome $d$ are implicated (for a review see Jünemann, 1997).

A form of cytochrome $d$ absorbing at $650 \mathrm{~nm}$, presumably an oxygenated form, has been observed in many other bacteria including Klebsiella pneumoniae (Smith et al., 1990) and Photobacterium phosphoreum (Konishi et al., 1986). In all cases, the form is remarkably stable (compared with the oxygenated complex of haemcopper type oxidases; e.g. Poole et al., 1979). However, nothing is known about the physiological significance of this form and whether it exists in growing cells. Therefore we have devised a modified diode-array spectrophotometer to investigate the effects of $\mathrm{O}_{2}$ supply on the redox poise and oxygenation in vivo of cytochromes $b, d$ and $c$ of $A$. vinelandii. A preliminary summary of some of this work has been published elsewhere (Kavanagh et al., 1995).

\section{METHODS}

Bacteria, culture and preparations of cell suspensions. $A$. vinelandii strain UW136 (a rifampicin-resistant derivative of strain UW; Bishop et al., 1980) and its kanamycin-resistant derivatives MK5 (carrying $c y d B:: \operatorname{Tn} 5-\mathrm{B} 20$ ) and MK8 (carrying cydR::Tn5-B20) (Kelly et al., 1990; Wu et al., 1997) were maintained on Burke's medium with $2 \%$ sucrose and $15 \mathrm{mM}$ ammonium acetate (BSN; Kelly et al., 1990) and subcultured monthly. Batch cultures were grown in $50 \mathrm{ml}$ BSN in Erlenmeyer flasks $(250 \mathrm{ml})$ and incubated at $30^{\circ} \mathrm{C}$ in air without shaking for $6 \mathrm{~h}$ and then on a rotary shaker (140 r.p.m.) for $17 \mathrm{~h}$. Cultures were inoculated ( $2 \%$ for UW136 and MK8; $4 \%$ for MK5) from cultures grown in an enriched Burke's-type medium (RM; Robson et al., 1984) that had been incubated as above.

Sucrose-limited chemostat cultures of strain MK8 were grown at a dilution rate of $0.1 \mathrm{~h}^{-1}$ in $\mathrm{N}$-free Burke's medium containing sucrose $(0.5 \%)$, nitrilotriacetic acid $(0.5 \mathrm{mM})$ and kanamycin $\left(1 \mu \mathrm{g} \mathrm{ml}^{-1}\right)$ contained in a $11 \mathrm{New}$ Brunswick Bioflo III fermenter with a working volume of $500 \mathrm{ml}$ and modified as described below for diode-array spectrophotometry. Growth was maintained at $\mathrm{pH} 7$, at $30^{\circ} \mathrm{C}$ and at dissolved $\mathrm{O}_{2}$ concentrations $(\mathrm{DOC})$ of 12 or $24 \mu \mathrm{M} \mathrm{O}$ as indicated. Due to the high respiratory activity of this strain, a DOC of $24 \mu \mathrm{M} \mathrm{O}_{2}$ was the highest we could easily achieve when using an agitation rate of about 500 r.p.m. and $80-90 \%$ $\mathrm{O}_{2}$ in $\mathrm{N}_{2}$ in place of air. Cultures were inoculated $(2 \%)$ from the RM culture grown as described above, and achieved a steady-state sucrose limitation even at $12 \mu \mathrm{M} \mathrm{O} \mathrm{O}_{2}$, which is below the $\mathrm{O}_{2}$ level at which Kelly et al. (1990) were able to grow this strain on plates. This difference probably resides in the more favourable rate of $\mathrm{O}_{2}$ transfer provided by the chemostat environment. Cells from batch cultures $(50 \mathrm{ml})$ were harvested by centrifugation $(15 \mathrm{~min}$ at $2000 \mathrm{~g})$ at $4^{\circ} \mathrm{C}$, washed in $50 \mathrm{ml}$ Burke's medium without carbon and fixed nitrogen sources and resuspended in $10 \mathrm{ml}$ of the same medium to give a five fold concentration. The cells were stored at $4^{\circ} \mathrm{C}$.

Biomass was estimated by protein content, which was calculated from the relationship of $\mathrm{OD}_{540}$ to bacterial protein (Smith et al., 1988).

Modifications to a Hewlett Packard HP 8452A diode-array spectrophotometer and Clark-type $\mathrm{O}_{2}$ electrode for recording absorption spectra in bacterial samples. Although oxidases (and all cytochromes) have intense and characteristic absorbance bands, their study in vivo is not trivial. The major experimental obstacle is that the absorbance bands are superimposed on, and therefore masked by, the scattering by the cells themselves of the measuring light from the sample. 


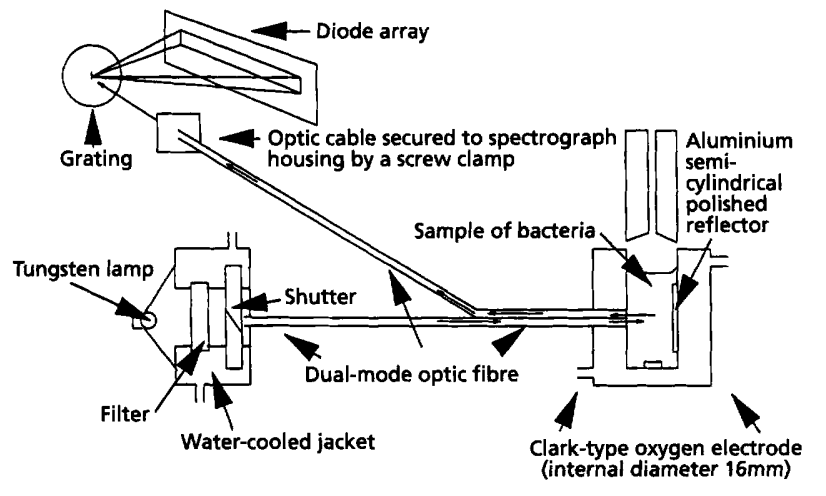

Fig. 1. Diagram of light path in modifications to the Hewlett Packard diode-array spectrophotometer and the Clark-type $\mathrm{O}_{2}$ electrode chamber for recording absorption spectra in bacterial samples retained in the $\mathrm{O}_{2}$ electrode chamber. The light source was a tungsten projector lamp (Philips type 6423, $15 \mathrm{~V}, 150 \mathrm{~W}$ ), mounted in the back of a water-cooled aluminium frame and powered by a highly stable DC source $(0-15 \mathrm{~V})$ fitted with a $10-$ turn potentiometer for accurate control of light intensity. Within the frame were mounted a light filter with a transmission range $475-980 \mathrm{~nm}$ (Oriel Scientific), an electromagnetically operated shutter (Magnetic), which was controlled through the existing shutter drive circuit of the spectrophotometer and the larger afferent arm of the bifurcated optic fibre. The efferent limb of the bifurcated optic fibre was abutted on to the window of the spectrograph and secured to the housing by a screw clamp. To deliver and return light to and from the bacterial sample, the dual-mode end of the optic fibre was mounted to penetrate the water jacket and inner wall of the perspex Clark-type $\mathrm{O}_{2}$ electrode chamber (Rank Bros), so as to be opposite a thin polished aluminium sheet, acting as reflector, that was placed against the inside wall of the chamber.

Scattering is most intense, and thus most problematic, at the lowest wavelengths. Routinely, these difficulties are overcome by two approaches. First, the sample cuvette is located close to the light detector so that as much of the scattered beam as possible is detected by the photomultiplier, diode array or other detector. Very few commercially available spectrophotometers offer this facility and are therefore unsuitable for observing cytochrome absorbance in vivo. Second, advantage is taken of the substantial absorbance changes that occur upon oxidation and reduction of the sample without major changes in the light scattering. Thus, a difference spectrum (most commonly reduced minus oxidized) reveals the cytochrome spectral features without observation of the light-scattering signal (Poole \& Bashford, 1987). Computing a derivative of the absolute spectrum (see below) also aids analysis by virtue of a marked narrowing of the absorbance bands. Further experimental difficulties arise if the sample is not easily contained in a cuvette suitable for measuring transmitted light. These have been generally overcome by the availability of fibre-optic light guides to bring the measuring beam to the sample and the reflected signal from the sample to the detector. For example, such light guides, in conjunction with UV/visible spectrophotometers, have been used to monitor the cytochrome content in steady-state growth of the $\mathrm{N}_{2}$ fixer Azorbizobium caulinodans (Pronk et al., 1993) and in conjuction with light-emitting diodes to estimate the oxygenation of leghaemoglobin in intact birdsfoot trefoil (Lotus corniculatus) nodules (Denison \& Layzell, 1991). In this study, we harnessed fibre-optic light guides to a diode-array spectro-

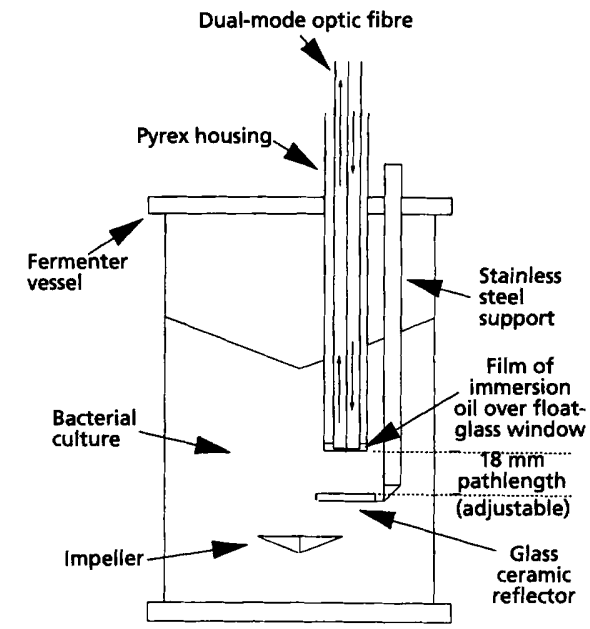

Fig. 2. Light path for monitoring cytochrome redox poise in a fermenter. A pyrex glass dip tube with a float glass end window and carrying, after autoclaving, the dual-mode end of the bifurcated fibre-optic cable resting in a drop of microscope immersion oil, was mounted in the head plate of the fermenter next to a stainless steel support on which was secured a glass ceramic reflector (Macor). The 'macor' reflector material reflects light uniformly, its thermal coefficient of expansion is suitable for repeated autoclaving in situ in the fermenter, and it is non-wettable and non-porous, which minimized microbial growth on its surface.

photometer. The latter has the advantage, when compared to a UV/visible spectrophotometer, of being able to make simultaneous measurements over a wide range of wavelengths.

We used an HP 8452A instrument $(470-1100 \mathrm{~nm})$. The modifications made for the purpose of in situ cytochrome analysis, using a bifurcated optic fibre to carry light to and from the sample (retained in a Clark-type $\mathrm{O}_{2}$ electrode chamber), are indicated in Fig. 1. Summaries of these modifications have appeared earlier (Cavinato et al., 1990, 1992); technical information can be provided by the authors on request. The sample $(7 \mathrm{ml})$ of bacterial suspension was stirred in the $\mathrm{O}_{2}$ electrode chamber, maintained at $30^{\circ} \mathrm{C}$ by water circulation, and where indicated, flushed with a stream of either air or $\mathrm{N}_{2}$. Power settings for the light source were adjusted, in the absence of the bacterial sample, to give maximum light intensity but within the recommended limits of the supplied Hewlett Packard software. Blanks were then recorded. The values of absorption of these, and subsequently those from the samples of bacteria, were converted to the second-order derivative with a smoothing factor of five by the supplied Hewlett Packard software. The negative value of the second-order derivative of absorbance was used to report the signal intensity at a particular wavelength (see Results). The wavelengths used for reporting the changes in signal intensity when varying the $\mathrm{O}_{2}$ supply were those giving maximum deflection in the second-order derivatives when the sample of cells was under anaerobiosis. They varied in different samples by 2 or $4 \mathrm{~nm}$.

Oxystat for controlling DOC in the Clark-type $\mathrm{O}_{2}$ electrode chamber. The maintenance of desired DOCs in the Clark-type $\mathrm{O}_{2}$ electrode chamber was achieved by the equipment previously described by Kavanagh \& Hill (1990), which uses feedback control of the magnetic stirrer by the electrode current. In earlier work, $\mathrm{O}_{2}$ detection was by photoemission 
from a photobacterium. In the present work, the $D C$ polarizing voltage required for the Clark-type $\mathrm{O}_{2}$ electrode was provided by the amplifier incorporated into this previously described equipment. A gas space retained above the sample in the Clark-type $\mathrm{O}_{2}$ electrode chamber was flushed with either air or $\mathrm{N}_{2}$ to bring the DOC near the required value, at which point the controller was switched on.

Additions to a New Brunswick Bioflo fermenter for in situ spectral analysis. The equipment for light delivery to, and collection from, the bacterial chemostat culture in a New Brunswick Bioflo fermenter is shown in Fig. 2. The path length of light could be adjusted to give optimum signals. Blanks were recorded before the fermenter was filled with medium or during growth by removing the optic fibre and placing it in a duplicate dip tube and reflector mounted outside the fermenter.

\section{RESULTS AND DISCUSSION}

\section{Detection of cytochromes in washed suspensions of A. vinelandii by diode-array reflectance spectrophotometry (DARS)}

To investigate the influence of $\mathrm{O}_{2}$ status on the redox poise of cytochrome $b d$, and in particular the occurrence of the stable oxygenated form of cytochrome $d$ in $A$. vinelandii, we employed DARS. Initially, we tested the efficacy of the modified diode-array spectrophotometer by measuring the cytochrome spectra of $\mathrm{N}_{2}$-sparged suspensions of bacterial cultures within the chamber of a Clark-type $\mathrm{O}_{2}$ electrode chamber (Fig. 1; Methods). Three strains of $A$. vinelandii known to synthesize different amounts of cytochrome $d$ (Kelly et al., 1990) were grown in batch culture with excess $\mathrm{NH}_{4}^{+}$until stationary phase, harvested, washed and resuspended in buffer as described in Methods. Strain MK5 carries a Tn5 insertion in $c y d B$ and synthesizes no cytochrome $b d$ (Kelly et al., 1990; Moshiri et al., 1991). Strain MK8 has a Tn5 insertion in cydR, encoding an Fnr-like transcriptional repressor of the $c y d A B$ operon and thus overproduces this oxidase (Wu et al., 1997; D'mello et al., 1997). Fig. 3 shows the second-order derivatives of spectra obtained from $\mathrm{N}_{2}$-sparged suspensions of these three strains. The second-order derivatives provided a means of observing absorption spectra in these turbid suspensions (see Methods). Absorption bands that appear positive (peaks) in the raw data appear as negatives (troughs) of narrower band width in the second-order derivatives (Butler \& Hopkins, 1970). In the absence of $\mathrm{O}_{2}$, when the cytochromes are reduced, cytochrome $d$ has a distinctive absorbance at $630 \mathrm{~nm}$. This absorbance in the second-order derivative appears as a trough at $630 \mathrm{~nm}$ in the wild-type (strain UW136) and is more pronounced in strain MK8, but is missing in strain MK5 (Fig. 3).

The narrowing of band widths afforded by the secondorder-derivative analysis gave a clear resolution of cytochromes $c(552 \mathrm{~nm})$ and $b(560 \mathrm{~nm})$. The scans of UW136 and MK8 (Fig. 3) also show differences in the relative sizes of the signals at $552 \mathrm{~nm}$ and at $560 \mathrm{~nm}$. The ratio of the depths of these troughs $(552 \mathrm{~nm}: 560 \mathrm{~nm})$ is lower in MK8 than in UW136. A similar difference was

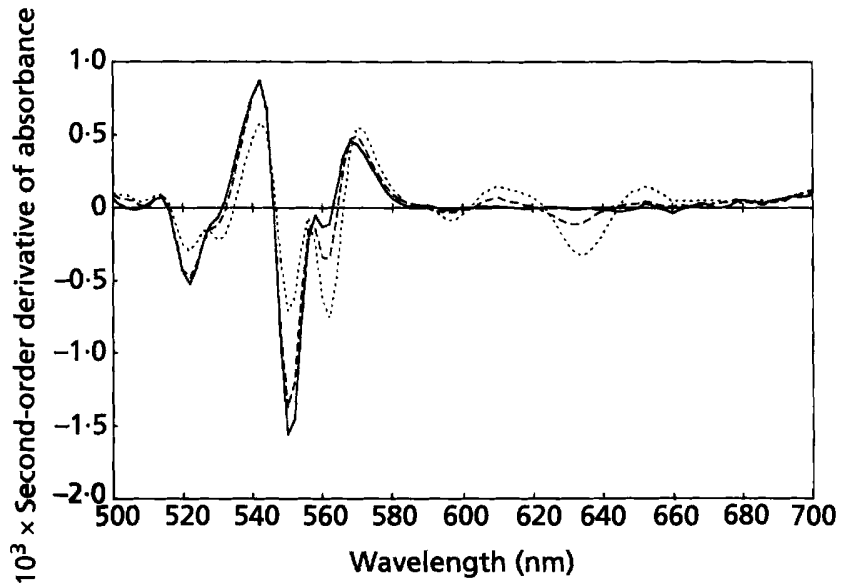

Fig. 3. Second-order derivatives of absorption spectra of suspensions of $A$. vinelandii strains stirred under $N_{2}$. Spectra of strains UW136 (dashed line), MK8 (dotted line) and MK5 (solid line) were recorded using the optics shown in Fig. 1. Batch cultures were grown, harvested and resuspended as described in Methods to give protein concentrations $\left(\mathrm{mg} \mathrm{ml}^{-1}\right)$ of 1.9 for UW136, 1.4 for MK8 and 2.0 for MK5. The suspensions were stored for $2 \mathrm{~d}$ at $4{ }^{\circ} \mathrm{C}$, and when placed in the Clark-type $\mathrm{O}_{2}$ electrode chamber, were supplemented with sucrose $(4.2 \mathrm{mM})$, and then stirred under $\mathrm{N}_{2}$.

found in the reduced minus oxidized difference spectra of these strains; in MK8 the ratio of cytochromes $c$ to $b$ $\left(A_{552}: A_{560}\right)$ was lower than in UW136 (Kelly et al., 1990). From this initial feasibility study, we concluded that the optics associated with the electrode chamber could distinguish the reduced forms of cytochromes $d, b$ and $c$.

Two aspects of this application of diode-array spectrophotometry limit the quantification of bacterial cytochromes to relative values rather than absolute ones. First, the path length is unknown due to light scattering by the bacteria. However, we found an apparent proportionality of signal intensity (e.g. at 560 and $630 \mathrm{~nm}$ ), when measured from the line drawn through zero to the bottom of the trough, with biomass concentrations (up to about $0.7 \mathrm{mg}$ protein $\mathrm{ml}^{-1}$ ) in $\mathrm{N}_{2^{-}}$sparged suspensions of UW136 or MK8 (data not shown). Because the intensity of a signal in a secondorder derivative spectrum is influenced by the natural bandwidth of the chromophore (Butler \& Hopkins, 1970) and because these bandwidths cannot be assumed to be equal, two different species in the same spectrum cannot be compared. However, these data demonstrate that the trough depth for the same species indicates relative amounts.

Furthermore, in second-order derivatives of absorbance spectra, the depth of a trough is influenced not only by the sharpness of the original peak but also by the accompanying positive shoulders of a closely occurring trough (Butler \& Hopkins, 1970). The latter is the case with the troughs at 552 and $560 \mathrm{~nm}$, which are attributed to cytochromes $c$ and $b$ respectively. Therefore caution 

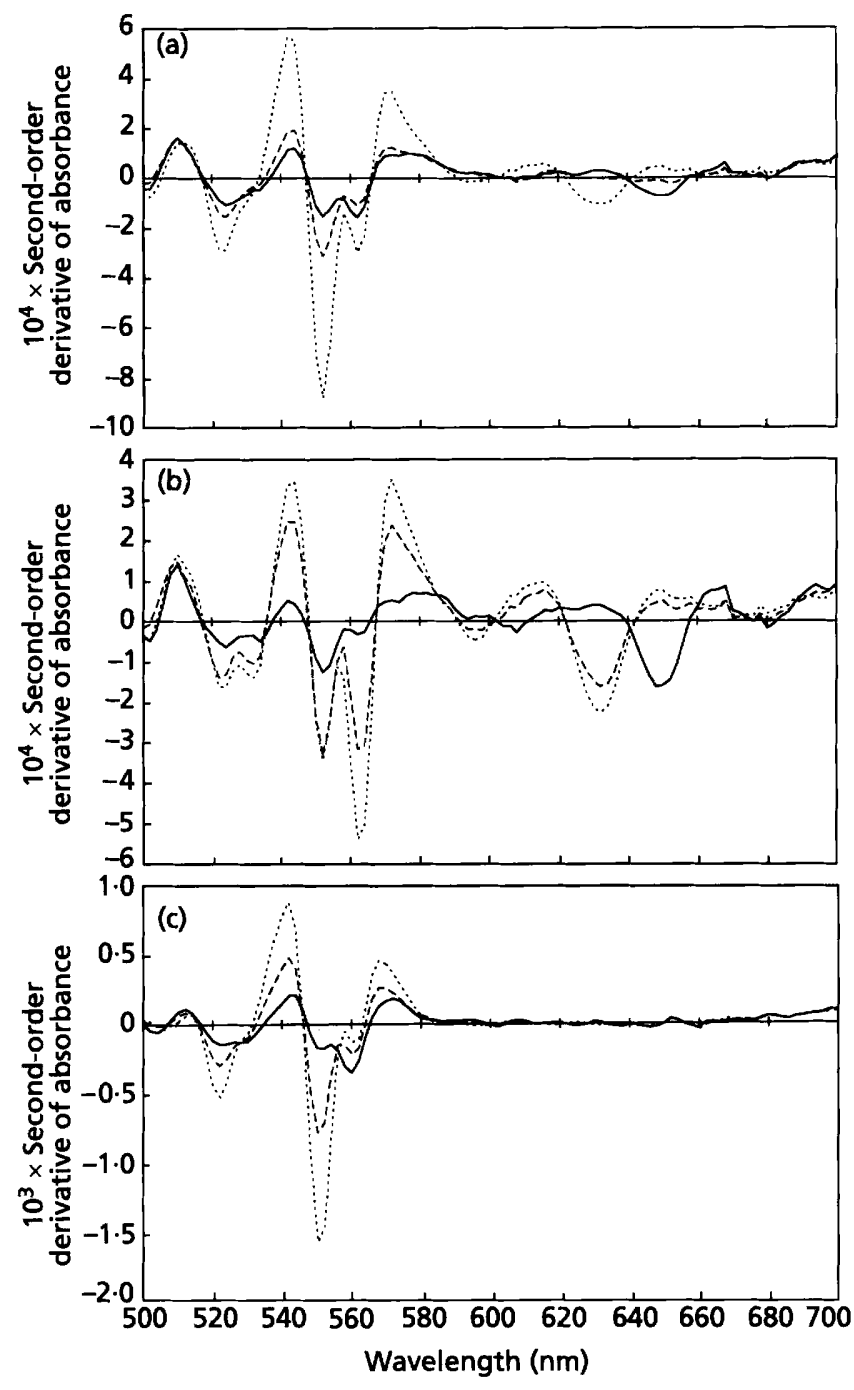

Fig. 4. Second-order absorption spectra showing transitions between fully oxygenated and fully reduced cytochromes in A. vinelandii strains. Suspensions of strains UW136 (a), MK8 (b) and MK5 (c) (grown, resuspended to give protein concentrations of $0.7,0.7$ and $2.0 \mathrm{mg} \mathrm{ml}^{-1}$ respectively and stored as indicated in Methods) were placed in the Clark-type $\mathrm{O}_{2}$ electrode chamber. They were supplemented with sucrose $(4.2 \mathrm{mM})$, and spectra were recorded, first when the suspensions were stirred under air (solid line) and then when the gas supply was changed to $\mathrm{N}_{2}$; a series of spectra were taken during the subsequent 2 min until the cytochromes became fully reduced (dotted line). For clarity only the fully oxidized spectrum, the fully reduced spectrum and one partially reduced representative spectrum (dashed line) are shown.

is required when interpreting the sizes of signals, as such overlaps could obscure isosbestic points.

\section{Influence of $\mathrm{O}_{2}$ supply on cytochrome redox state in washed suspensions}

Fig. 4 shows the second-order derivatives of a series of repeated scans recorded when suspensions of washed cells of strains UW136 (Fig. 4a), MK8 (Fig. 4b) or MK5 (Fig. 4c) were stirred in the presence of added sucrose (approx. $4.2 \mathrm{mM}$ ), first under a stream of air, and then under a stream of $\mathrm{N}_{2}$ in the Clark-type electrode. To obtain changes over a sufficiently long time period (from 2 to $4 \mathrm{~min}$ ) so that sequential scans showed the intermediate redox states (of which, for clarity, only one is shown in each panel of Fig. 4), suspensions were stored for about $2 \mathrm{~d}$ at $4{ }^{\circ} \mathrm{C}$; changes that occurred in suspensions used earlier were too rapid to be resolved. During the storage of these suspensions, no change was observed in cytochrome complement, when viewed under either $\mathrm{N}_{2}$ or air. Since storage was in the absence of carbon and energy sources, the slowing of redox changes probably arose from a decline in rate of electron donation.

Certain spectral changes visible in UW136 (Fig. 4a) and particularly in MK8 (Fig. 4b) can be unambiguously attributed to components of the cytochrome $b d$ complex. These are at $630 \mathrm{~nm}$ (reduced cytochrome $d$ ), $650 \mathrm{~nm}$ (oxygenated cytochrome $d$ ) and $595 \mathrm{~nm}$ (highspin cytochrome $\left.b_{595}\right)$. A proportion of the change at $560 \mathrm{~nm}$ must also be due to the low-spin cytochrome $b$ component of this oxidase complex. These assignments are unaltered by a redistribution of electron flux from ubiquinol that might occur when an oxidase with higher affinity for oxygen takes more of the electron flux at low oxygen concentration. As the $\mathrm{O}_{2}$ supply declined, the oxygenated $(650 \mathrm{~nm})$ form was diminished and the reduced $(630 \mathrm{~nm})$ form appeared. There is a clear isosbestic point for cytochrome $d$ at $642 \mathrm{~nm}$. The reduction of cytochrome $b_{595}$ is also just recognizable as the appearance of a small signal at $595 \mathrm{~nm}$ as the $\mathrm{O}_{2}$ supply declined; as expected, this signal is more marked in the spectra of MK8 than of UW136. The increase in the signal intensity at $552 \mathrm{~nm}$ is attributed to the reduction of cytochromes $c$, and that at $560 \mathrm{~nm}$ is in part attributed to reduced low-spin cytochrome $b_{560}$. The increases in absorbance at 595 and $560 \mathrm{~nm}$ accompanying the decline in $\mathrm{O}_{2}$ supply indicate that initially, under air, the cytochrome $b d$ complex in strains UW136 and MK8 was in the oxygenated state $\left(d_{650}\right)$. This is presumably the stable form of the oxidase - species 7 in the scheme of Jünemann (1997), in which cytochromes $b_{560}$ and $b_{595}$ are oxidized (and their reduction is observed in the experiment), whereas cytochrome $d$ must be reduced, since only in this state can it bind oxygen to give the $650 \mathrm{~nm}$ form. As expected, the scans for MK5 (Fig. 4c) showed no signal at $650 \mathrm{~nm}$, as this strain does not make cytochrome $b d$. The only increase in signal that occurred upon the decrease in $\mathrm{O}_{2}$ supply was at $552 \mathrm{~nm}$, attributed to reduction of cytochromes $c$.

Having observed the one-electron-reduced oxygenated form of cytochrome $b d$, we analysed the sequence of scans for changes in redox poise as the $\mathrm{O}_{2}$ supply declined. Fig. 5 shows the data for the complete sequences of scans. Here the changes in signal intensities at wavelengths near $552 \mathrm{~nm}$ (attributed to cytochromes c), $560 \mathrm{~nm}$ (attributed to cytochrome $b_{560}$ and other $b$ type cytochromes), $595 \mathrm{~nm}$ (attributed to cytochrome $b_{595}$ ), $630 \mathrm{~nm}$ (attributed to the deoxygenated cytochrome $d^{2+}$ ) and $650 \mathrm{~nm}$ (attributed to the oxygenated 
(a)

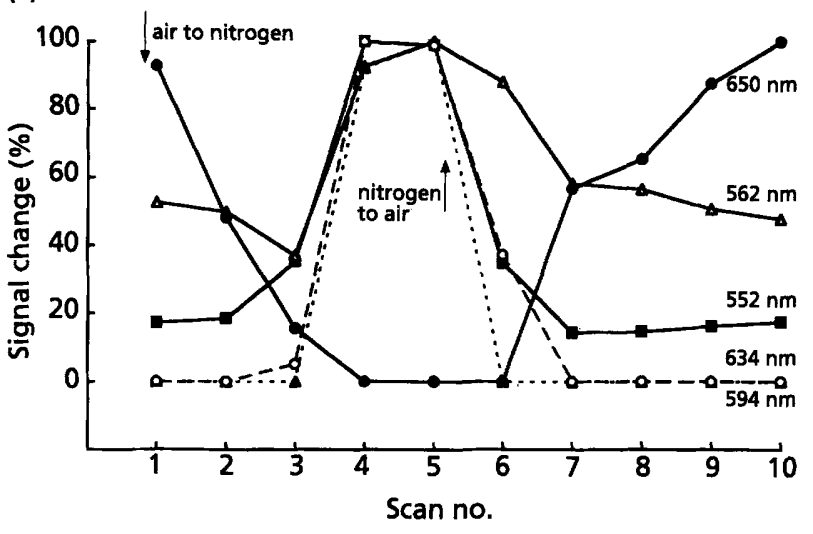

(b)

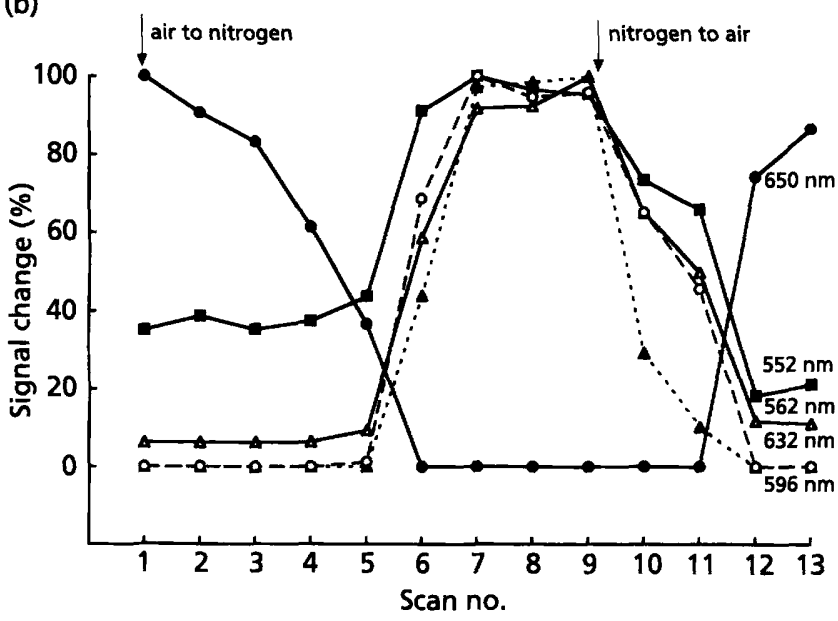

Fig. 5. Changes in cytochrome signal intensity at various wavelengths in suspensions of $A$. vinelandii strains during a decline and then an increase in $\mathrm{O}_{2}$ supply. A series of spectra of strains UW136 (a) and of MK8 (b) were taken (as described in the legend to Fig. 4) over a time period of about $4 \mathrm{~min}$. The gas supply was changed from air to $\mathrm{N}_{2}$ just before the first scan shown. Spectra were recorded until no further change was seen, when the gas supply was changed back to air (after scan 5 in a and scan 9 in b); recording continued until there was no further change. Signal sizes at the wavelengths shown are shown as percentages of the maximum deflection recorded during the series. Signal sizes at 594/596 nm $(\Delta)$ and $632 / 634 \mathrm{~nm}$ (O) partly overlap in (a) and (b). These maxima for the measurement from baseline to trough in the second-order derivatives of absorbance were, for UW136 and MK8 respectively, at wavelengths of: $552 \mathrm{~nm}, 8.9 \times 10^{-4}$ and $3.6 \times 10^{-4} ; 560 \mathrm{~nm}$, $3.0 \times 10^{-4}$ and $5.4 \times 10^{-4} ; 595 \mathrm{~nm}, 0.13 \times 10^{-4}$ and $0.47 \times 10^{-4}$. $630 \mathrm{~nm}, 1.0 \times 10^{-4}$ and $2.4 \times 10^{-4} ; 650 \mathrm{~nm}, 0.77 \times 10^{-4}$ and $1.6 \times 10^{-4}$. The scans showing partially reduced cytochromes in Fig. 4 were scan 3 in (a) and 6 in (b).

cytochrome $d^{2+}$ ) are expressed as percentages of the maximum observed at that wavelength for the sequence. In both strains UW136 (Fig. 5a) and MK8 (Fig. 5b), upon changing the gas supply to the chamber from air to $\mathrm{N}_{2}$, the level of oxygenated cytochrome $d^{2+}$ (signal at $650 \mathrm{~nm}$ ) started to decline well before the reduction of cytochromes $b_{560}$ and $b_{595}$ (increases in the signals near
$595 \mathrm{~nm}$ and $560 \mathrm{~nm}$ ) were discernible. In Fig. 5(a) for example, the level of oxygenated cytochrome $d^{2+}$ (signal at $650 \mathrm{~nm}$ ) had declined to about $15 \%$ of its initial value before significant change had occurred in the reduction of cytochromes $b_{560}$ and $b_{595}$ (increases in signals at 594 and $634 \mathrm{~nm}$ ). Thus, the decrease occurring at $650 \mathrm{~nm}$ was apparently due to those associated with the oneelectron-reduced oxygenated cytochrome $b d$. Subsequently, the reduction of cytochromes $c, b_{560}$ and $b_{595}$ (increase in signals at 552, 562 and $594 \mathrm{~nm}$ respectively) and the appearance of the deoxygenated cytochrome $d^{2+}$ (increase in signal at $634 \mathrm{~nm}$ ) occurred almost in parallel (Fig. 5a). The changes in the reduction of $b_{595}$ (signal near $595 \mathrm{~nm}$ ) are clearer in the data for strain MK8 (Fig. $5 b$ ). In the data for scan 3 of strain UW 136 (Figs 4a and 5a) the sizes of signals attributed to cytochrome $d^{2+}$, in both the oxygenated and the deoxygenated forms (signals at 650 and $634 \mathrm{~nm}$ ), indicated that a large proportion of cytochrome $d$ appeared to be in a form that did not absorb at either of these wavelengths. This poise was quite difficult to record, but was observed on two other occasions with this strain. A somewhat similar poise was seen in strain MK8 (scan 5 in Fig. 5 b). Since each series of measurements was recorded in a single sample in which the total cytochrome $d$ content was constant and since both the $630 \mathrm{~nm}$ and $650 \mathrm{~nm}$ signals were weak, we conclude that we were observing a species of cytochrome $d$ that absorbed at neither 630 nor $650 \mathrm{~nm}$.

When the $\mathrm{N}_{2}$ supply was replaced by air, there was a general reversal in the redox and oxygenation changes in both strains UW136 and MK8 (Fig. 5). The oxidation of cytochromes $c, b_{560}$ and $b_{595}$ (decline in signals near 552, 560 and $590 \mathrm{~nm}$, respectively) and disappearance of the deoxygenated form of cytochrome $d^{2+}$ (signal near $630 \mathrm{~nm}$ ) all started well before the oxygenated cytochrome $d^{2+}$ (signal at $650 \mathrm{~nm}$ ) was discernible. During this decline, scans were recorded for strains UW136 (scan 6 in Fig. 5a) and MK8 (scan 11 in Fig. 5b), where more than $50 \%$ of the cytochrome $d$ could not be accounted for at either 630 or $650 \mathrm{~nm}$. Again cytochromes $b_{560}$ and $b_{595}$ appeared to be oxidized when the cytochrome $d^{2+}$ was oxygenated, indicating that the signal at 650 was due to the oxygenated one-electronreduced cytochrome $b d$.

These changes in signal sizes with alterations in $\mathrm{O}_{2}$ supply demonstrate that the transformations in redox states of cytochromes $b_{595}$ and $b_{560}$ are not closely coupled to the transitions of cytochrome $d$ between the oxygenated one-electron-reduced species absorbing at $650 \mathrm{~nm}$ and a species which seems not to absorb significantly at either 630 or $650 \mathrm{~nm}$. In contrast, they do appear to be coupled to the appearance and disappearance of the reduced cytochrome $d$ (absorbing at $630 \mathrm{~nm}$ ). Kauffman \& van Gelder (1973) came to the same conclusion from following changes in absorbance between 600 and $700 \mathrm{~nm}$ during transitions in redox states of A. vinelandii phosphorylating particles.

Electron transfer from quinol in the $E$. coli enzyme occurs via haem $b_{558}$ to the other two haems which 


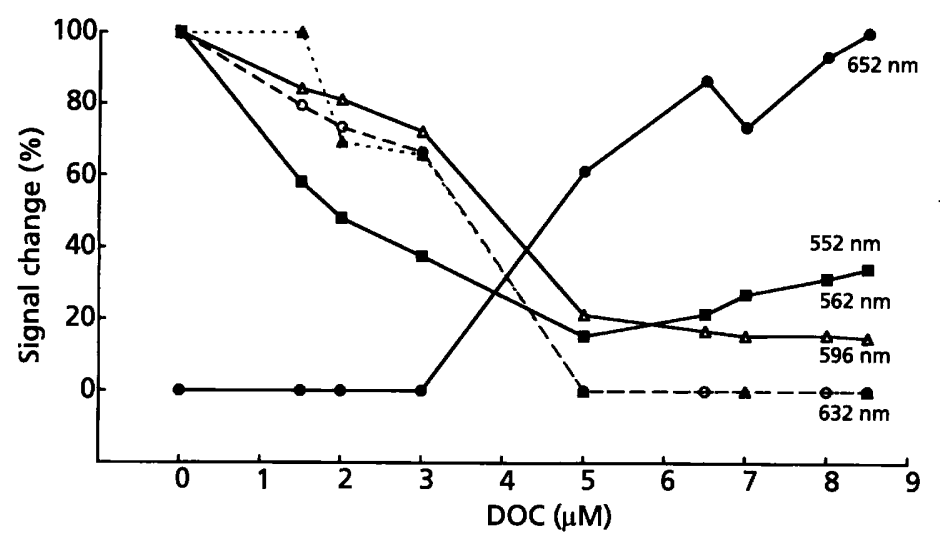

Fig. 6. Correlation of signal sizes at selected wavelengths with the DOC in a suspension of $A$. vinelandii strain MK8. The suspension $\left(0.44 \mathrm{mg}\right.$ protein $\left.\mathrm{ml}^{-1}\right)$ was prepared for spectroscopy as described in the legend to Fig. 4, and was stirred under $\mathrm{N}_{2}$ or under air in the Clark-type $\mathrm{O}_{2}$ electrode chamber using the optics shown in Fig. 1. The stirring rate was automatically controlled to maintain a series of rising preset DOC values (see Methods), each for about 4 min, during which time the spectra were recorded. The data are plotted as a percentage of the maximum deflection as described in the legend to Fig. 5, and are shown with the maximum signal for the following wavelengths: $552 \mathrm{~nm}(\square), 3.2 \times 10^{-4}$; $562 \mathrm{~nm}(\triangle), 4.0 \times 10^{-4} ; 596 \mathrm{~nm}(\Delta), 2.7 \times 10^{-5} ; 632 \mathrm{~nm}(0), 1.5 \times 10^{-4} ;$ and $652 \mathrm{~nm}(0), 1.0 \times 10^{-4}$.

probably reside in a common pocket where oxygen is reduced (Hill et al., 1993). Spectral data on ligand binding to the $A$. vinelandii enzyme have confirmed that the haem $b_{595}$ has a lower affinity for $\mathrm{O}_{2}$ than does haem $d$ (D'mello et al., 1994b; Jünemann \& Wrigglesworth, 1995 ), and that $\mathrm{O}_{2}$ can migrate from the oxygenated ferrous complex of cytochrome $d$ to the haem $b_{595}$ (D'mello et al., 1994b). Flash-flow rapid kinetics with the three-electron-reduced $E$. coli enzyme have shown (Hill et al., 1994) that although $\mathrm{O}_{2}$ rapidly binds to cytochrome $d$ (giving a form that absorbs at $650 \mathrm{~nm}$ ) it rapidly decays to a species identified by Kahlow et al. (1991) as oxy-ferryl $\left(d_{680}\right)$. Moreover, steady-state kinetics (Jünemann et al., 1995; Jünemann \& Rich, 1996) of the $A$. vinelandii enzyme suggest that the oxygenated one-electron-reduced enzyme $\left(d_{650}\right)$ develops when reducing equivalents are exhausted; further, upon restoration of electron donation, the very short-lived oxygenated three-electron-reduced enzyme $\left(d_{650}\right)$, observed by Hill et al. (1994), provides re-entry into the fast cycle of enzyme turnover. An earlier scheme of Kahlow et al. (1991) includes the oxygenated cytochrome $d_{650}$ within enzyme turnover, but does not differentiate between the one- and three-electronreduced oxygenated forms of the enzyme.

The redox state of cytochrome $d$ giving the nearfeatureless species between 630 and $650 \mathrm{~nm}$ is unclear, but the oxidized form ( $\left.\mathrm{Fe}^{\mathrm{III}}\right)$ was proposed to have such properties in the scheme of Poole et al. (1983). In this case, the oxidase would be in the redox state $b_{560}^{3+}$, $b_{595}^{3+}, d^{3+}$. The resolution of our spectra was insufficient to observe changes at $680 \mathrm{~nm}$ (see Fig. 4b), which would identify the oxy-ferryl species of cytochrome $d$ (Kahlow et al., 1991; Hill et al., 1994). In this case, the oxidase would be in the redox state $b_{560}^{3+}, b_{595}^{3+}, d^{4+} \mathrm{O}^{2-}$, which corresponds to intermediate 3 in the scheme of Jünemann (1997). In our experiments, three different redox states of the cytochrome $b d$-type oxidase were apparent: initially under air, the one-electron-reduced oxygenated form, $b_{560}^{3+}, b_{595}^{3+}, d^{2+} \mathrm{O}_{2}$, (intermediate 7 in the Jünemann, 1997, scheme), then as the $\mathrm{O}_{2}$ supply declined, the unidentified species indicated above (either $b_{500}^{3+}, b_{595}^{3+}, d^{3+}$ or $\left.b_{560}^{3+}, b_{595}^{3+}, d^{4+} \mathrm{O}^{2-}\right)$ changing to the fully reduced form $b_{560}^{2+}, b_{595}^{2+}, d^{2+}$ (unligated) (intermediate 6 in the Jünemann, 1997, scheme). These changes were reversed when the $\mathrm{O}_{2}$ supply was reintroduced. In the catalytic cycle proposed by Jünemann et al. (1995), the stable one-electron-reduced oxygenated species of cytochrome $d$ (absorbing at $650 \mathrm{~nm}$ ) does not contribute to enzyme turnover associated with $\mathrm{O}_{2}$ reduction. This species is referred to by Jünemann (1997) as intermediate 7 or the 'oxygenated (as prepared)' form to indicate its occurrence in preparations of the purified oxidase complex. It enters the cycle slowly, by way of reduction, to form the very short-lived oxygenated reduced enzyme $\left(b_{560}^{2+}, b_{595}^{2+}, d^{2+} \mathrm{O}_{2}\right)$, and only re-forms when reducing power becomes exhausted. Our observations are consistent with a slow rate of reduction of the one-electron-reduced oxygenated form, suggesting that this form is not an intermediate of turnover in vivo.

\section{Relationship of cytochrome redox state in washed suspensions with DOC}

To determine the DOC at which these redox changes were occurring, an oxystat was attached to the $\mathrm{O}_{2}$ electrode. The changes in DOC during the transitions depicted in Figs 4 and 5 occurred within the range $0-10 \mu \mathrm{M}$, but at a rate too fast to correlate satisfactorily the prevailing DOC with the redox states of the cytochromes. The oxystat controlled the stirring rate to maintain preset DOC values in the suspension (see Methods). A suspension of strain MK8, which had been sparged with $\mathrm{N}_{2}$, was stirred in air and second-order- 


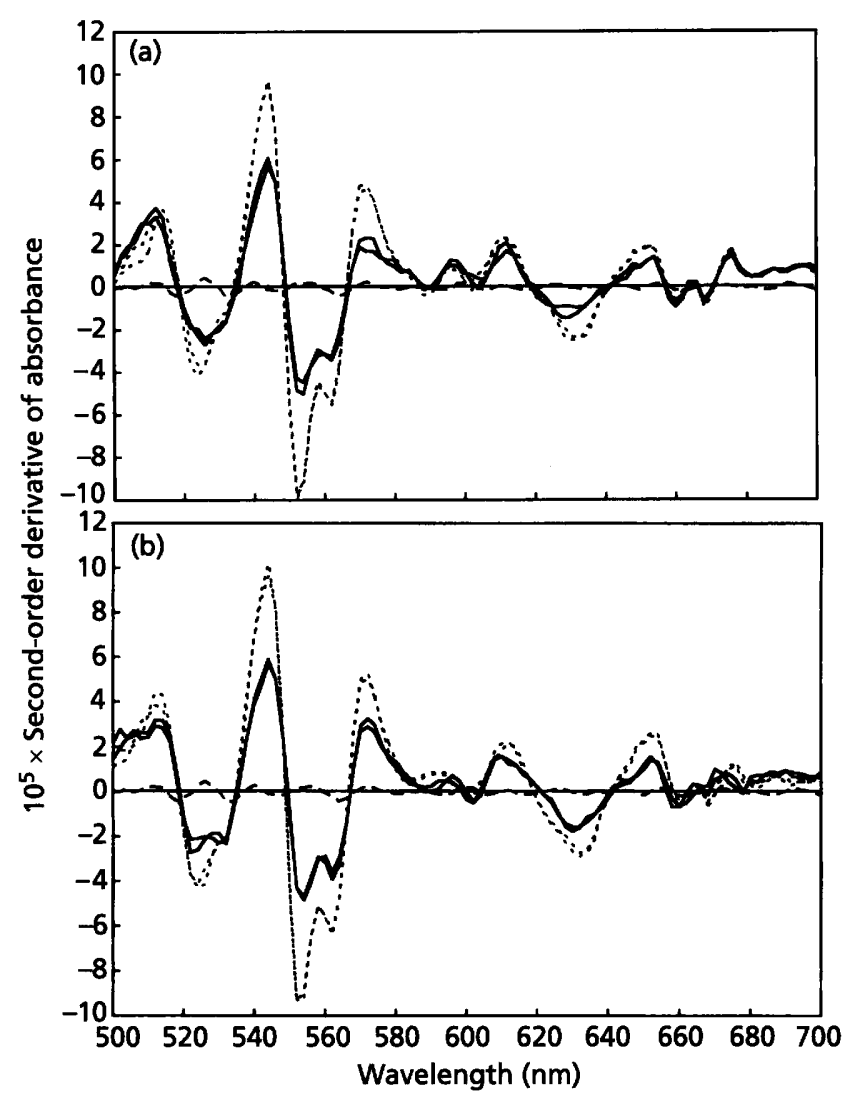

Fig. 7. Spectra of $A$. vinelandii strain MK8 during growth in the modified New Brunswick Bioflo fermenter. Sucrose-limited $\mathrm{N}_{2}-$ fixing steady states $\left(0.13 \mathrm{mg}\right.$ protein $\left.\mathrm{ml}^{-1}\right)$ were established as described in Methods and maintained at either $12 \mu \mathrm{M}$ (a) or $24 \mu \mathrm{M}$ (b) DOC. Spectra were recorded during steady-state growth (solid lines) and after the $\mathrm{O}_{2}$ supply was turned off (dotted lines) as described in the text. Two representatives of repeated scans and the blank (dashed lines) are shown.

derivative spectra were recorded while the DOC was maintained at various increasing levels, each held for about 4 min. Fig. 6 shows the changes, at representative wavelengths, that occurred in the signal intensities; they are shown as percentages of the maximum deflection observed at a particular wavelength. Initially, the signals attributed to cytochromes $c, b_{560}, b_{595}$ and $d$ (at 552, 562, 596 and $632 \mathrm{~nm}$ respectively), started to decline when the DOC was hardly above zero. The 'featureless' spectrum of cytochrome $d$, where the signals at 632 and $652 \mathrm{~nm}$ were smallest, occurred near a DOC of $4 \mu \mathrm{M}$ (Fig. 6). Unfortunately, maintenance of the DOC between 2 and $4 \mu \mathrm{M}$ was difficult to achieve. At $5 \mu \mathrm{M}$ DOC, cytochromes $c$ (signal at $552 \mathrm{~nm}$ ), $b_{560}$ (signal at $562 \mathrm{~nm}$ ) and $b_{595}$ (signal at $596 \mathrm{~nm}$ ) appeared to be largely oxidized, whereas the signal at $652 \mathrm{~nm}$ indicated that not all the cytochrome $d$ could be accounted for in the oxygenated form. Above $5 \mu \mathrm{M}$ DOC, the signal attributed to the oxygenated cytochrome $d$, in this case the one-electron-reduced cytochrome $b d$, continued to increase and this increase appeared to parallel a slight reduction in cytochromes $c$ (increase in the $552 \mathrm{~nm}$ signal). Because the changes in redox state of these cytochromes took place close to the limit of sensitivity of the Clark-type $\mathrm{O}_{2}$ electrode, the precise DOC at which they occurred could not be assessed. Nevertheless, the range appeared to be close to the value for the apparent $K_{\mathrm{m}}$ for $\mathrm{O}_{2}$ for the $b d$-type oxidase of $5 \mu \mathrm{M}$ which has been found in similar suspensions of whole cells of strains UW136 and MK8 (D'mello et al., 1994a).

\section{Redox poise of cytochromes during steady-state growth}

In washed cells supplied with sucrose, the one-electronreduced oxygenated species was observed at DOCs above $3 \mu \mathrm{M}$ (Fig. 6). To determine whether this species occurred during growth, we established a carbon- and energy-limited chemostat fed with excess $\mathrm{O}_{2}$. Under conditions of $\mathrm{O}_{2}$ excess, the cytochrome $b d$-type oxidase plays an important role in removing $\mathrm{O}_{2}$, particularly during diazotrophy. To estimate the redox poise of cytochromes under these conditions, a $\mathrm{N}_{2}$-fixing sucrose-limited chemostat of MK8 growing at $12 \mu \mathrm{M}$ $\mathrm{O}_{2}$, was established in a fermenter that was fitted to deliver and to collect light for analysis by DARS as shown in Fig. 2.

Upon achieving a steady state, spectra were recorded. Examples of two repeated spectra are shown as secondorder derivatives in Fig. 7(a) and show a trough at $630 \mathrm{~nm}$. To determine whether cytochrome $d$ was in the fully reduced state, the stirrer was turned off and the gas supply to the culture was changed to $\mathrm{N}_{2}$. When the $\mathrm{O}_{2}$ electrode registered zero, repeated scans were recorded over a period of not more than $5 \mathrm{~min}$. The stirrer and gas supply were then reinstated slowly so as to prevent the DOC from rising above the set point. A comparison of the scans taken when the DOC was zero with those taken during steady-state growth (Fig. 7a) revealed that cytochromes $d, c$ and $b_{560}$ were partially reduced during sucrose-limited growth at $12 \mu \mathrm{M} \mathrm{O}_{2}$. Furthermore, there was no negative deflection at $650 \mathrm{~nm}$, indicating that there appeared to be little, if any, cytochrome $d$ in the oxygenated form during steady-state growth. To determine the effect of increasing the $\mathrm{O}_{2}$ supply, spectra were also recorded during sucrose-limited growth at $24 \mu \mathrm{M} \mathrm{O}_{2}$. Representatives of the data are shown in Fig. 7 (b). As found with the population growing at $12 \mu \mathrm{M}$ $\mathrm{O}_{2}$, there was no evidence that the oxygenated species of cytochrome $d$ (anticipated trough at $650 \mathrm{~nm}$ ) was present, and the cytochromes were again partially reduced during steady-state growth.

The quality of the spectra was insufficient to compare the amount of cytochromes present in the populations at different DOCs, but there appeared to be no gross changes upon a doubling in the DOC. The finding that, during steady-state sucrose-limited growth at both 12 and $24 \mu \mathrm{M} \mathrm{O}_{2}$, the average redox state of cytochromes in vivo appears to be partially reduced suggests that the rate of electron supply to the respiratory chain and the rate of oxidase activity are regulated to maintain a low but sufficient level of $\mathrm{O}_{2}$ for energy conservation. This 
finding is similar to that reported for succinate-limited $\mathrm{N}_{2}$-fixing growth of Azorbizobium caulinodans maintained at DOCs between 0.1 and $3.5 \%$ (Pronk et al., 1993). Cytochromes $c$ and $b$ were partially reduced in such cultures. These authors used a dual-beam spectrophotometer with fibre optics to deliver and collect light through the wall of the fermenter. The fermenter had to be encased in a light-proof box. In comparison, our application of DARS has two advantages: (1) encasing the sample in a light-proof box is unnecessary, and (2) spectral acquisition is very fast so that transient changes over a wide absorbance range can be recorded.

\section{Conclusions and further opportunities}

Our study of the effect of $\mathrm{O}_{2}$ status on the cytochrome oxygenation and redox poise of the $A$. vinelandii cytochrome $b d$-type oxidase in vivo using DARS has revealed the following features. First, when the $\mathrm{O}_{2}$ supply was varied to washed cells supplied with sucrose, three different redox forms of the oxidase were sufficiently long-lived for presumptive identification. They were (1) the relatively stable one-electron-reduced oxygenated form $\left(b_{560}^{3+}, b_{595}^{3+}, d^{2+} \mathrm{O}_{2}\right),(2)$ a form where cytochrome $d$ apparently had no absorbance at either 650 or $630 \mathrm{~nm}$ but cytochromes $b$ were oxidized $\left(b_{560}^{3+}\right.$, $\left.b_{595}^{3+}\right)$ and (3) the fully reduced form $\left(b_{560}^{2+}, b_{595}^{2+}, d^{2+}\right)$. Changes in cytochrome $d$ from the form with no absorbance at either 650 or $630 \mathrm{~nm}$ to the reduced form with an absorbance at $630 \mathrm{~nm}$ appeared to correlate with the reduction of cytochromes $b_{595}$ and $b_{560}$. These changes were relatively rapid. It is possible that the 'featureless' cytochrome $d$ is the ferric form (' $d_{\mathrm{x}}$ ') rather than the oxy-ferryl species $\left(d^{4+} \mathrm{O}^{2-}\right)$. Unfortunately, our equipment was not sensitive enough at $680 \mathrm{~nm}$ to detect the latter. These changes, we suggest, are consistent with the scheme of Jünemann et al. (1995) and Jünemann (1997), where the oxygenated form of cytochrome $d$ in the one-electron-reduced enzyme does not contribute to the enzyme turnover. Second, changes in the redox poise of cytochrome $d$ occurred at a DOC which appeared to coincide approximately with the apparent $\mathrm{O}_{2}$ affinity for the oxidase in similar washed cell suspensions (D'mello et al., 1994a). This may indicate that the build-up of a relatively stable intermediate occurs at the DOC supporting half maximum turnover for a given rate of electron donation. Third, during steady-state growth in $\mathrm{N}_{2}$-fixing populations, cytochromes $d, b$ and $c$ were partially reduced, which is consistent with the ability of $A$. vinelandii to show an immediate, as well as an adaptive, response of respiration to sudden increases in $\mathrm{O}_{2}$ supply (see Poole \& Hill, 1997; Hill, 1992; and references therein). In such growing populations we could not detect the oxygenated form of cytochrome $d$ (absorbing at $650 \mathrm{~nm}$ ).

We have not exploited all the opportunities for application of DARS. With regard to $A$. vinelandii physiology, comparisons of the redox poise of cytochromes during steady-state growth of $\mathrm{N}_{2}$-fixing populations with those assimilating $\mathrm{NH}_{4}^{+}$should yield some further insight into the role of respiration during diazotrophy. The effect of respiratory inhibitors on cytochrome redox state in membrane preparations could also be studied with the modification to the Clark-type $\mathrm{O}_{2}$ electrode. For transitions of cytochrome redox state in whole cells occurring near the limit of sensitivity of the Clark-type $\mathrm{O}_{2}$ electrode, a more sensitive $\mathrm{O}_{2}$ probe is required. A possibility is a time-shared arrangement to allow for the measurement and control of $\mathrm{O}_{2}$ by the photoemission of a photobacterium (Kavanagh \& Hill, 1990) as well as the analysis of light absorbance by DARS.

\section{ACKNOWLEDGEMENTS}

This work was supported by BBSRC grant-in-aid to the John Innes Centre, BBSRC Linked Research Grants (nos LR29/548 and GO4903) and INTAS-RFBR Grant 951-1259. S.E.E held a cooperative studentship and J.B.C. held Fulbright and Guggenheim fellowships. We thank Dr G. Wu for helpful discussions.

\section{REFERENCES}

Bishop, P. E., Jarlenski, D. M. \& Hetherington, D. R. (1980). Evidence for an alternative nitrogen fixation system in $A z o$ tobacter vinelandii. Proc Natl Acad Sci USA 77, 7342-7346.

Butler, W. L. \& Hopkins, D. W. (1970). Higher derivative analysis of complex absorption spectra. Photochem Photobiol 12, 439-450.

Cavinato, A. G., Mayes, D. M., Ge, Z. \& Callis, J. B. (1990). Noninvasive method for monitoring ethanol in fermentation processes using fibre-optic near-infrared spectroscopy. Anal Chem 62, 1977-1982.

Cavinato, A. G., Ge, Z., Callis, J. B. \& Finger, R. E. (1992). Real-time measurement of microbial metabolism in activated sludge samples. In Pollution Prevention in Industrial Processes: the Role of Process Analytical Chemistry, pp. 222-228. Edited by J. J. Breen \& M. J. Dellarco. Washington, DC: American Chemical Society.

Denison, R. F. \& Layzell, D. B. (1991). Measurement of legume nodule respiration and $\mathrm{O}_{2}$ permeability by noninvasive spectrophotometry of leghemoglobin. Plant Physiol 96, 137-143.

D'mello, R., Hill, S. \& Poole, R. K. (1994a). Determination of the oxygen affinities of the terminal oxidases in Azotobacter vinelandii using the deoxygenation of oxyleghaemoglobin and oxymyoglobin: cytochrome $b d$ is a low-affinity oxidase. Microbiology 140, 1395-1402.

D'mello, R., Palmer, S., Hill, S. \& Poole, R. K. (1994b). The cytochrome $b d$ terminal oxidase of Azotobacter vinelandii: low temperature photodissociation spectrophotometry reveals reactivity of cytochromes $b_{595}$ and $d$ with both carbon monoxide and oxygen. FEMS Microbiol Lett 121, 115-120.

D'mello, R., Hill, S. \& Poole, R. K. (1996). The cytochrome bd quinol oxidase in Escherichia coli has an extremely high oxygen affinity: implications for regulation of activity in vivo by oxygen inhibition. Microbiology 142, 755-763.

D'mello, R., Purchase, D., Poole, R. K. \& Hill, S. (1997). Expression and content of terminal oxidases in Azotobacter vinelandii grown with excess $\mathrm{NH}_{4}^{+}$are modulated by $\mathrm{O}_{2}$ supply. Microbiology 143, 231-237.

Green, G. N., Fang, H., Lin, R.-J., Newton, G., Mathers, M., Georgiou, C. D. \& Gennis, R. B. (1988). The nucleotide sequence of 
the cyd locus encoding the two subunits of the cytochrome $d$ terminal oxidase complex of Escherichia coli. J Biol Chem 263, 13138-13143.

Hill, S. (1992). Physiology of nitrogen fixation in free-living heterotrophs. In Biological Nitrogen Fixation, pp. 86-134. Edited by G. Stacey, R. H. Burris \& H. J. Evans. New York \& London: Chapman \& Hall.

Hill, J. J., Alben, J. O. \& Gennis, R. B. (1993). Spectroscopic evidence for a heme-heme binuclear center in the cytochrome $b d$ ubiquinol oxidase from Escherichia coli. Proc Natl Acad Sci USA 90, 5863-5867.

Hill, B. C., Hill, J. J. \& Gennis, R. B. (1994). The room temperature reactions of carbon monoxide and oxygen with the cytochrome bd quinol oxidase from Escherichia coli. Biochemistry 33, 15110-15115.

Junemann, S. (1997). Cytochrome $b d$ terminal oxidase. Biochim Biophys Acta 1321, 107-127.

JUnemann, S. \& Rich, P. R. (1996). Does the cytochrome bd terminal oxidase complex have a 'pulsed form'? Biochem Soc Trans 24, 400S.

Junemann, S. \& Wrigglesworth, J. M. (1995). Cytochrome bd oxidase from Azotobacter vinelandii: purification and quantitation of ligand binding to the oxygen reactive site. $J$ Biol Chem 270, 16213-16220.

Jünemann, S., Butterworth, P. J. \& Wrigglesworth, J. M. (1995). A suggested mechanism for the catalytic cycle of cytochrome $b d$ terminal oxidase based on kinetic analysis. Biochemistry 34, 14861-14867.

Kahlow, M. A., Zuberi, T. M., Gennis, R. B. \& Loehr, T. M. (1991). Identification of a ferryl intermediate of Escherichia coli cytochrome $d$ terminal oxidase by resonance Raman spectroscopy. Biochemistry 30, 11485-11489.

Kauffman, H. F. \& van Gelder, B. F. (1973). The respiratory chain of Azotobacter vinelandii . I. Spectral properties of cytochromed. Biochim Biophys Acta 305, 260-267.

Kavanagh, E. P. \& Hill, S. (1990). The automatic maintenance of low dissolved oxygen using a photobacterial oxygen sensor for the study of microaerobiosis. J Appl Bacteriol 69, 539-549.

Kavanagh, E. P., Callis, J. B. \& Hill, S. (1995). Application of diodearray spectrophotometry for the analysis of bacterial cytochromes in vivo. In Nitrogen Fixation: Fundamentals and Applications, pp. 217. Edited by I. A. Tikhonovich, N. A. Provorov, V. I. Romanov \& W.E. Newton. London: Kluwer Academic Publishers.

Keilin, D. (1966). The History of Cell Respiration and Cytochrome. Cambridge: Cambridge University Press.

Kelly, M. J. S., Poole, R. K., Yates, M. G. \& Kennedy, C. (1990). Cloning and mutagenesis of the genes encoding the cytochrome $b d$ terminal oxidase complex in Azotobacter vinelandii: mutants deficient in the cytochrome $d$ complex are unable to fix nitrogen in air. J Bacteriol 172, 6010-6019.

Kita, K., Konishi, K. \& Anraku, Y. (1984). Terminal oxidases of the Escherichia coli aerobic respiratory chain. II. Purification and properties of cytochrome $b_{558}-d$ complex from cells grown with limited oxygen and evidence of branched electron-carrying systems. J Biol Chem 259, 3375-3381.

Kolonay, J. F., Moshiri, F., Gennis, R. B., Kaysser, T. M. \& Maier, R. J. (1994). Purification and characterisation of the cytochrome bd complex from Azotobacter vinelandii: comparison to the complex from Escherichia coli. J Bacteriol 176, 4177-4181.

Konishi, K., Ouchi, M., Kita, K. \& Horikoshi, I. (1986). Purification and properties of a $b_{560}-d$ complex, a terminal oxidase of the aerobic respiratory chain of Photobacterium phosphoreum. J Biochem 99, 1227-1236.

Leung, D., van der Oost, J., Kelly, M., Saraste, M., Hill, S. \& Poole, R. K. (1994). Mutagenesis of a gene encoding a cytochrome o-like terminal oxidase of Azotobacter vinelandii: a cytochrome o mutant is aero-tolerant during nitrogen fixation. FEMS Microbiol Lett 119, 351-358.

Moshiri, F., Chawla, A. \& Maier, R. J. (1991). Cloning, characterization, and expression in Escherichia coli of the genes encoding the cytochrome $d$ oxidase complex from Azotobacter vinelandii. J Bacteriol 173, 6230-6241.

Poole, R. K. \& Bashford, C. L. (1987). Spectra. In Spectrophotometry and Spectrofluorimetry - a Practical Approach, pp. 23-48. Edited by D. A. Harris \& C. L. Bashford. Oxford: IRL Press.

Poole, R. K. \& Hill, S. (1997). Respiratory protection of nitrogenase activity in Azotobacter vinelandii - roles of the terminal oxidases. Biosci Rep 17, 303-317.

Poole, R. K., Waring, A. J. \& Chance, B. (1979). The reaction of cytochrome $o$ in Escherichia coli with oxygen. Biochem $J$ 184, 379-389.

Poole, R. K., Kumar, C., Salmon, I. \& Chance, B. (1983). The $650 \mathrm{~nm}$ chromophore in Escherichia coli is an 'oxy-' or oxygenated compound, not the oxidized form of cytochrome oxidase $d$ : an hypothesis. J Gen Microbiol 129, 1335-1344.

Pronk, A. F., Boogerd, F. C., Stoof, C., Oltmann, F., Stouthamer, A. \& van Verseveld, H.W. (1993). In situ determination of the reduction levels of cytochromes $b$ and $c$ in growing bacteria: a case study with $\mathrm{N}_{2}$-fixing Azorhizobium caulinodans. Anal Biochem 214, 149-155.

Robson, R. L., Chesshyre, J., Wheeler, C., Jones, R., Woodley, P. \& Postgate, J. R. (1984). Genome size and complexity in Azotobacter chroococcum. J Gen Microbiol 130, 1603-1612.

Smith, A., Hill, S. \& Anthony, C. (1988). A haemoprotein is not involved in the control by oxygen of enteric nitrogenase synthesis. $J$ Gen Microbiol 134, 1499-1507.

Smith, A., Hill, S. \& Anthony, C. (1990). The purification, characterisation and role of the $d$-type cytochrome oxidase of Klebsiella pneumoniae during nitrogen fixation. J Gen Microbiol 136, 171-180.

Wu, G., Hill, S., Kelly, M. J. S., Sawers, G. \& Poole, R. K. (1997). The $c y d R$ gene product, required for regulation of cytochrome $b d$ expression in the obligate aerobe Azotobacter vinelandii, is an Fnr-like protein. Microbiology 143, 2197-2207.

Yang, T. (1986). Biochemical and biophysical properties of cytochrome o of Azotobacter vinelandii. Biochim Biophys Acta 848, 342-351.

Yates, M. G. (1988). The role of oxygen and hydrogen in nitrogen fixation. In The Nitrogen and Sulphur Cycles, pp. 383-416. Edited by J. A. Cole \& S. Ferguson. Cambridge: Cambridge University Press.

Received 27 November 1997; revised 6 March 1998; accepted 30 March 1998. 